\title{
50 AÑOS DE TRASPLANTE DE CORAZÓN La operación que enmudeció al mundo y cambió para siempre el concepto de muerte
}

\author{
Ricardo Zalaquett \\ División de Enfermedades Cardiovasculares \\ Facultad de Medicina \\ Pontificia Universidad Católica de Chile
}

\section{Resumen}

Cuando el 3 de diciembre de 1967 Christiaan Barnard efectuó el primer trasplante de corazón no solo efectuó una operación que enmudeció al mundo sino que también cambió el concepto de muerte para siempre. Pero esta operación fue la culminación de un proceso que se inició con Alexis Carrel en 1910 y que no solo incumbe a la cirugía, sino que también a la inmunología y la infectología, así como a la ética, la filosofía y la teología.

Como en todos los grandes avances de la cirugía, es posible reconocer 3 grandes etapas en el desarrollo histórico del trasplante cardiaco: investigativa, clínica y moderna, las cuales se revisan en esta publicación.

Correspondencia:

Dr. Ricardo Zalaquett S.

Diagonal Paraguay 362, Piso 7

Santiago, Chile

rzalaque@med.puc.cl 


\section{YEARS AFTER THE FIRST HEART TRANSPLANT The operation that stunned the world and for ever changed the concept of death}

When on December 3, 1967, Christiaan Barnard performed the first human-to-human heart transplant, he not only performed an operation that stunned the world, but it also changed for ever the concept of death. This operation was the culmination of a process initiated by Alexis Carrel in 1910 concerning not only surgery but also immunology and infectious diseases as well as ethics, philosophy and theology.

In the historical development of heart transplantation, as in all major advances in surgery, it is possible to recognize 3 eras: the research, the clinical and the modern eras, which are reviewed in this paper.

Keywords: Heart transplantation; History, Medicine; Immunology; Brain death 
El domingo 3 de diciembre de 1967 el mundo fue impactado por una noticia espectacular y sobrecogedora proveniente de Ciudad del Cabo, Sudáfrica: CHRISTIAAN NEETHLING BARNARD, cirujano del Hospital GROOTE SCHUUR de dicha ciudad, había trasplantado con éxito el corazón de un ser humano a otro ser humano (Figura 1).

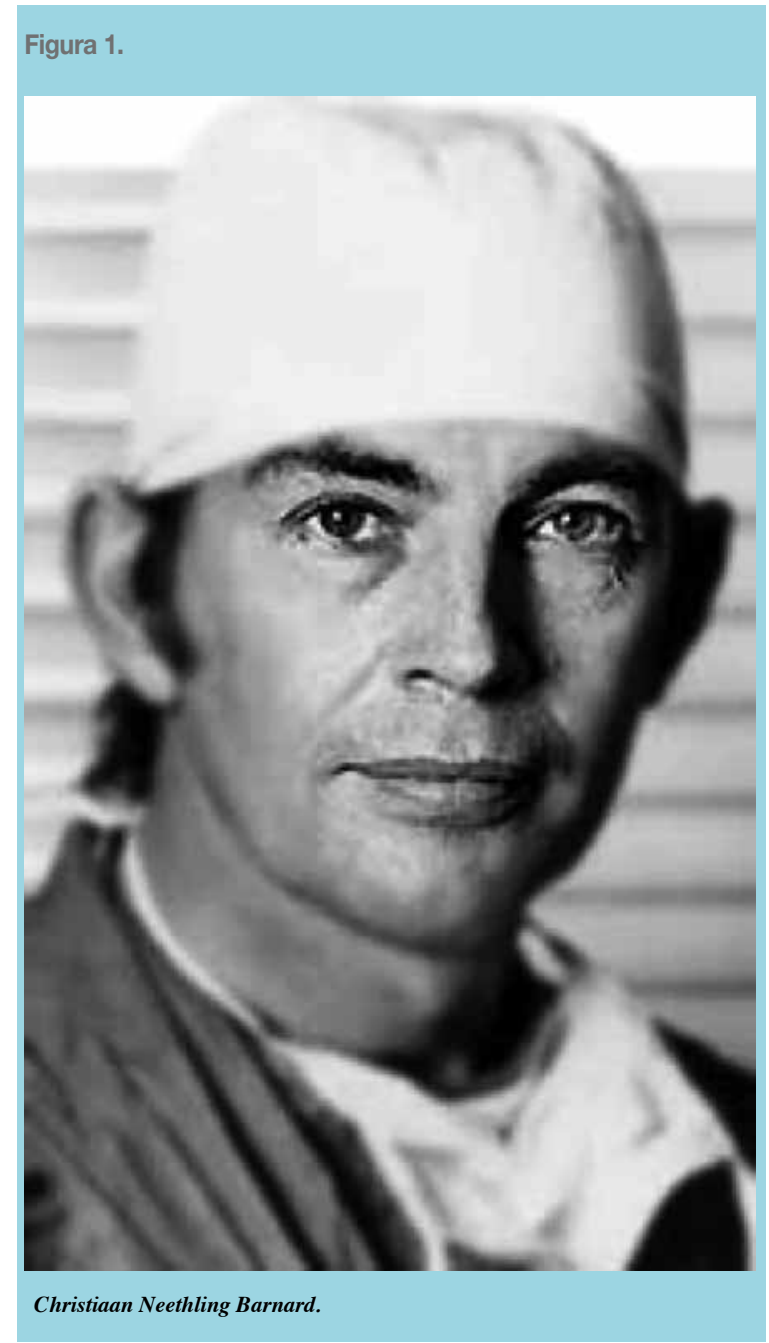

El receptor era LOUIS WASHKANSKY, comerciante de 54 años, hombre corpulento y optimista, postrado en una cama de dicho hospital por una insuficiencia cardiaca. La donante era una joven oficinista de 25 años, DENISE ANN DARVALL, atropellada junto a su madre, por un automovilista, quedando con el cráneo aplastado. Su padre donó, a nombre de ella, además del corazón, los riñones. Uno de estos fue enviado a un hospital distante a 36 kilómetros y trasplantado a un niño de 10 años, JONATHAN VAN WYK, que se aprontaba a morir por una insuficiencia renal.
Para evitar el rechazo del corazón de Denise por Louis, se usó una combinación de irradiación local, hidrocortisona, azotihiaprina, prednisona y actinomicina-C. Se tomaron todas las medidas de esterilidad imaginables, pero Washkansky falleció 18 días después, la madrugada del 21 de diciembre, de una neumonía por pseudomonas ${ }^{1}$.

Barnard no se desanimó, ni menos se amilanó. Antes de 2 semanas, el 2 de enero de 1968, realizó su segundo trasplante. El receptor fue el dentista PHILIP BLAIBERG y el donante el mulato CLIVE HAUPT. Así, en pleno apartheid, el corazón de un hombre de raza negra, como antes el de una mujer, latió en un hombre blanco, en este último caso, por casi 2 años, exactamente 563 días, siendo Blaiberg la primera persona que egresó viva de un hospital tras someterse a un trasplante cardiaco.

El 28 de junio de 1968, JORGE KAPLAN MEYER, en el Hospital ALMIRANTE NEFF, de Viña del Mar, realizó el primer trasplante cardiaco en Chile (Figura 2). La paciente fue MARIA ELENA PEÑALOZA, costurera de 24 años con una insuficiencia cardiaca secundaria a una valvulopatía. María Elena sobrevivió 6 meses, para morir luego de una infección. Este fue el tercer trasplante cardiaco hecho en Latinoamérica y María Elena la segunda mujer trasplantada de corazón en el mundo.

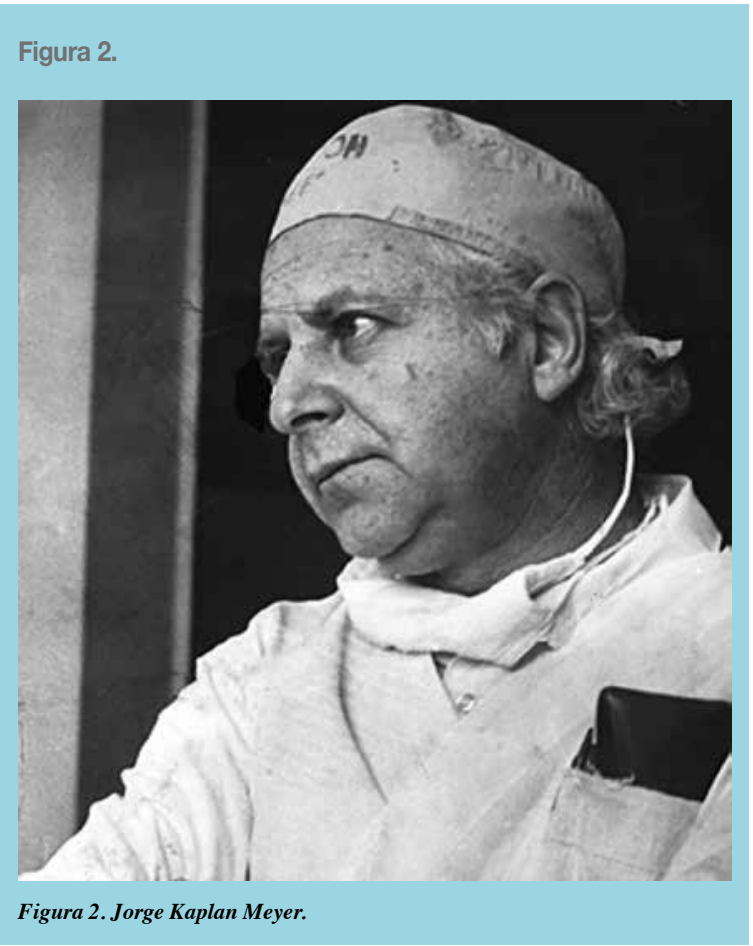


La historia del trasplante de corazón es una historia de nuestro tiempo, que abarca no solo a la cirugía, sino que también a la inmunología y a la infectología, y, muy especialmente, a la ética, la filosofía y la teología, ya que cambió para siempre el concepto de muerte que hasta entonces se tenía. Como en todos los grandes avances de la cirugía es posible reconocer 3 grandes etapas en el desarrollo histórico del trasplante cardiaco: investigativa, clínica y moderna ${ }^{2,3}$.

La etapa investigativa. La etapa investigativa del trasplante de corazón abarca más de 100 años. Se inicia con ALEXIS CARREL en 1890 con sus experimentos en anastomosis vasculares y que culmina con su célebre publicación, junto a CHARLES GUTHRIE, "The Trasplantation of Veins and Organs", en la que describe numerosas nuevas operaciones, entre estas, el primer trasplante heterotópico de corazón ${ }^{4}$. Carrel trasplantaba el corazón al cuello de un animal utilizando la arteria carótida y la vena yugular. Sin embargo, si bien las arterias coronarias eran perfundidas, el corazón trasplantado no efectuaba ningún apoyo circulatorio efectivo. Luego de Carrel hay un "silencio" de casi 20 años hasta que en 1933, MANN, de la Clínica Mayo, comunica 2 técnicas quirúrgicas de trasplante cardiaco heterotópico ${ }^{5}$. Mann y colaboradores en su publicación hacen un comentario en relación al rechazo, reconociendo que el autotrasplante se acompañaba en general de éxito, pero el homotrasplante en general originaba un rechazo que llevaba al fracaso.

Si bien Carrel y Mann fundan las bases históricas experimentales del trasplante de corazón, quien realmente estuvo adelantado a su tiempo fue el cirujano ruso VLADIMIR DEMIKHOV, que es el primero en efectuar trasplantes cardiacos auxiliares ("piggyback") en perros, ya en 1946, con sobrevidas de hasta 32 días. Pero, más aún, Demikhov es el primero en efectuar un trasplante cardiaco ortotópico experimental con éxito, en tiempos en que el concepto de hipotermia no había sido introducido y la máquina corazón-pulmón no había sido inventada aún. Sus trabajos, además, proveyeron las primeras evidencias de que un corazón trasplantado podía asumir función de bomba en el animal receptor. Pero, Demikhov no publicó en inglés, por lo que permaneció ignorado por el mundo occidental ${ }^{2,3}$. De hecho, el trasplante cardiaco desapareció de la literatura anglosajona en 1933 con la comunicación de Mann y solo reaparece casi 20 años después, en 1951, con MARCUS, WONG y LUISADA, de Chicago ${ }^{6}$. Estos investigadores desarrollan una elaborada técnica en la que utilizan 3 perros: un donante, un receptor y un tercero que sostiene el corazón del donante mientras

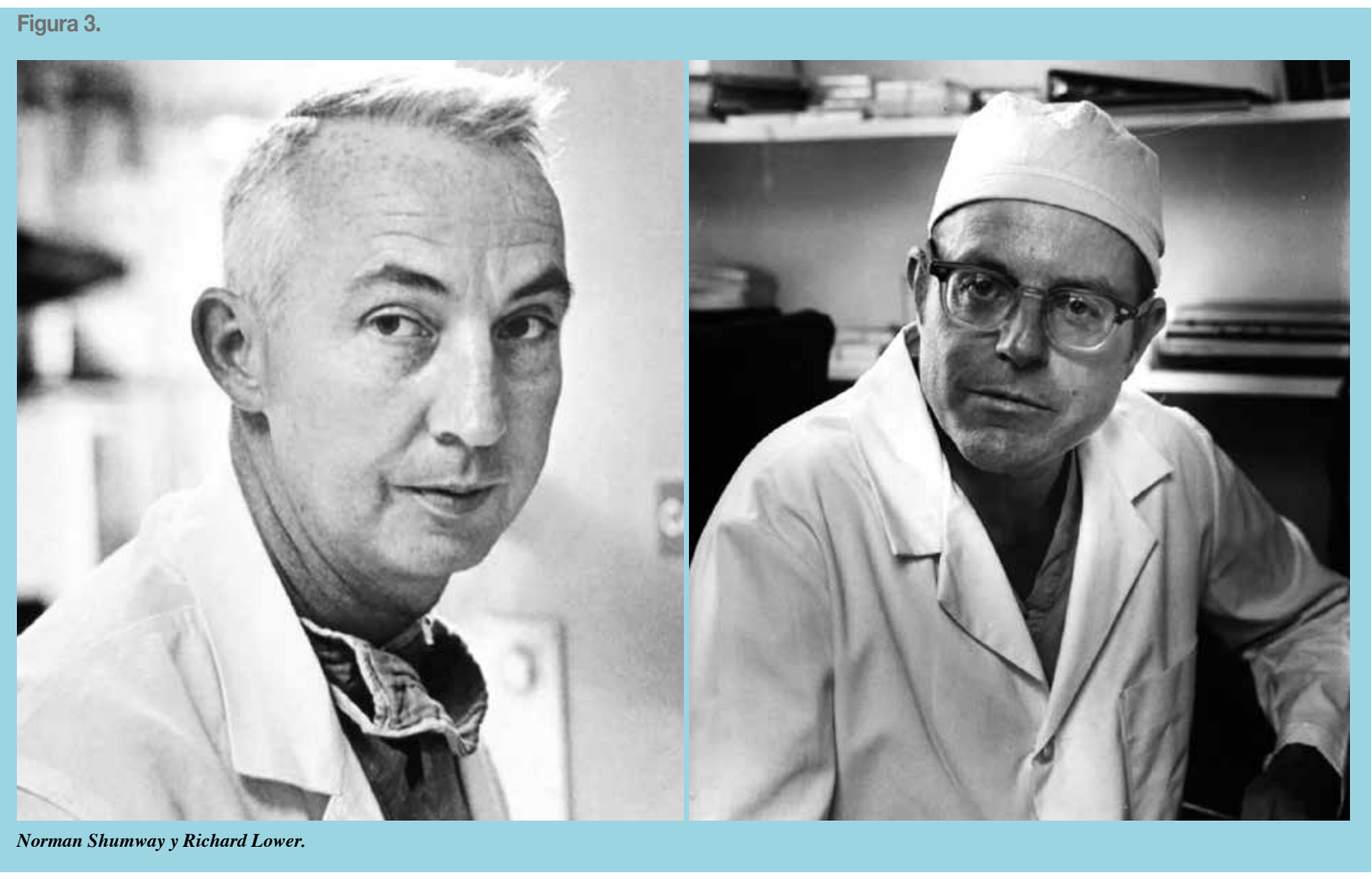


este permanece desconectado de la circulación. Con esto, Marcus y colaboradores introdujeron el primer método de preservación del corazón donante. A partir de esta comunicación de 1951, el trasplante cardiaco se quedó para siempre en la literatura experimental.

El 23 de diciembre de 1954 se produjo un avance que marca el desarrollo histórico del trasplante de órganos en general. Ese día, MURRAY, MERRILL y HARRISON, en el hospital PETER BENT BRIGHAM, en Boston, efectúan el primer trasplante de riñón en gemelos monocigóticos ${ }^{7}$. El éxito de esta operación fue un gran impulso para el trasplante cardiaco, lo que junto a la aparición de nuevas tecnologías en la cirugía cardiaca en general, como la hipotermia y la máquina de circulación extracorpórea, permitieron una mayor y más larga sobrevida de los animales de experimentación ${ }^{8}$. Con esto, sin embargo, se hizo evidente un problema mucho mayor: el rechazo tisular.

En 1957, los investigadores de la Universidad de Mississippi toman la delantera, utilizando por primera vez una máquina de circulación extracorpórea para sus experimentos en animales, y culminando en 1964 con el primer trasplante cardiaco en un ser humano, utilizando como donante a un chimpancé, aunque sin éxito, falleciendo el paciente una hora después ${ }^{9,10}$.

En 1960, por así decirlo, irrumpe el grupo de NORMAN SHUMWAY y RICHARD LOWER (Figura 3), de la Universidad de Stanford, dando inicio a una serie de publicaciones en las que comunican importantes lo$\operatorname{gros}^{11}$. Ese año publican un trabajo clásico en el que describen sus experimentos en homotrasplante cardiaco ortotópico en perros, utilizando circulación extracorpórea e introduciendo la técnica de preservación auricular parcial ("cuff auriculares"). Los resultados fueron impresionantes y la sobrevida de los animales ya no se midió en horas sino que en días, con lo que la técnica de cuff auricular se convirtió en el estándar para investigadores y cirujanos, siendo conocida hasta hoy como la "Técnica de Shumway". Pero, al mismo tiempo, toman clara conciencia del problema de rechazo del homoinjerto, sosteniendo que no podrá ser evitado hasta que su naturaleza sea mejor entendida. Predicen que cuando esto ocurra se encontraran los medios para modificar la producción de antígenos homólogos o la respuesta inmunológica del huésped, sin dañar a este o al injerto 2,3 .

Shumway y colaboradores, en el intertanto, orientaron sus esfuerzos a perfeccionar la técnica quirúrgica, y, con sorprendente visión de futuro, a las técnicas de preservación del corazón. Así, una vez demostrado fehacientemente que el corazón extirpado podía ser reimplantado para cumplir su función de bomba nuevamente, los esfuerzos fueron destinados al mayor de los problemas: EL RECHAZO TISULAR.

Gran parte del conocimiento temprano del rechazo se originó de los trabajos experimentales en animales en trasplante renal, que datan de la primera y segunda década del siglo pasado, los que establecieron que la falla del riñón trasplantado era debida a una "incompatibilidad biológica" entre el donante y el receptor. Más tarde, durante la segunda guerra mundial, los trabajos de PETER MEDAWAR van a revolucionar todo lo conocido en relación al trasplante de órganos: Medawar va a desarrollar y aplicar, por primera vez, el concepto de "Inmunología" al trasplante, a partir a su vez, de los conceptos de "antígeno" y "anticuerpo", que ya se conocían ${ }^{12}$. En 1944, Medawar publica un trabajo clásico en trasplante experimental de piel de conejo, introduciendo aquí el término de "RECHAZO"13. Medawar desarrolla varios conceptos fundamentales al respecto, como el rechazo "humoral" y el rechazo "celular". A comienzo de los años 50, Medawar sugiere que los recientemente descubiertos corticosteroides podrían prevenir o atenuar el rechazo. Sin embargo, las técnicas de inmunosupresión se van a desarrollar lentamente. No es hasta 1962, año en que JOSEPH MURRAY y colaboradores, comunican "el trasplante renal exitoso en recipientes condicionados", que se inicia el tratamiento inmunosupresor moderno ${ }^{14}$. Un año antes se había demostrado experimentalmente que la Azothioprina prolongaba la durabilidad de los riñones trasplantados y en 1960 se había introducido ya un tratamiento combinado de Methotrexato, Cyclofosfamida y Prednisona para el tratamiento del rechazo renal, el que hasta entonces era tratado solo con radioterapia. Rápidamente estos conceptos y técnicas inmunosupresoras se extendieron al trasplante cardiaco experimental, dando resultados alentadores en cuanto a durabilidad del injerto, pero a la vez se hacen evidentes las complicaciones infecciosas así como las derivadas de la toxicidad de estas drogas. También, a comienzos de los años 60 se experimenta con constituyentes del suero hasta producir la globulina antilinfocitaria 2,3 .

La etapa clínica. Como ya señalamos, el primer intento de trasplante cardiaco en un ser humano se efectuó en 1964 en la Universidad de Mississippi, por un equipo liderado por JAMES HARDY ${ }^{10}$. Los obstácu- 
los para efectuar un trasplante de corazón entre seres humanos en ese entonces eran inmensos. Puesto que la técnica quirúrgica a utilizar era experimental y los riesgos altísimos y mortales, solo podría intentarse en un paciente moribundo por insuficiencia cardiaca. Por otro lado, como el concepto de "muerte cerebral" aún no era aceptado, para usar un corazón humano toda actividad eléctrica y mecánica tenía que haber cesado definitivamente antes de que el corazón donante pudiera ser resecado. Así, en la práctica, 2 personas tendrían que morir simultáneamente, una por falla cardiaca y la otra con un corazón normal adecuado para una donación. Es por esto de que en la eventualidad de que un receptor en estas condiciones se presentase, pero con un eventual donante aún vivo, el equipo de la Universidad de Mississippi había decidido que se utilizaría el corazón de un chimpancé, como sucedió el 23 de enero de 1964. Si bien el corazón trasplantado comenzó a latir en forma sostenida, resultó ser proporcionalmente muy pequeño, por lo que no fue capaz de manejar todo el retorno venoso del receptor, falleciendo este una hora después de haber salido de circulación extracorpórea.

Tres días después de que CHRISTIAAN BARNARD el 3 de diciembre de 1967 dejara, desde Ciudad del Cabo, mudo y atónito al resto del mundo, un segundo trasplante se llevó a cabo en el MAIMONIDES MEDICAL CENTER, en Brooklyn, Nueva York, por ADRIAN KANTROWITZ, quien había desarrollado ya, junto a su hermano ingeniero, el balón intraaórtico de contrapulsación y había liderado el primer intento de trasplante de corazón entre 2 seres humanos en la misma institución, el 29 de junio de $1966^{15}$. En esa oportunidad el receptor era un lactante con un corazón univentricular y el donante un recién nacido anencefálico, pero la operación fue abortada en el pabellón de operaciones por falta de apoyo del resto de los médicos involucrados. Ese 6 de diciembre de 1967 el donante fue igualmente un recién nacido anencefálico, pero el receptor fue ahora un lactante de 3 semanas con una atresia tricúspidea. La operación se efectuó bajo hipotermia y paro circulatorio, y si bien el corazón recuperó ritmo sinusal, el niño falleció horas más tarde. Exactamente un mes después, SHUMWAY y su equipo, quienes tanto habían experimentado en el laboratorio y de lo que en gran medida se había beneficiado BARNARD, llevaron a cabo su primer trasplante de corazón en un ser humano ${ }^{16}$. Sin embargo, la operación fue técnicamente muy demandante y con múltiples complicaciones postoperatorias, falleciendo el paciente el día 15 de su postoperatorio por sepsis a gram-negativo. En mayo de 1968, DENTON COOLEY, en BAYLOR COLLEGE OF MEDICINE, inicia su programa de trasplante de corazón, obteniendo una sobrevida significativamente mayor a la observada hasta entonces ${ }^{17}$. Sin embargo, estos resultados no se reproducían en el resto de la comunidad cardioquirúrgica, a pesar del gran entusiasmo de esta, lo que había significado que en un año se habían efectuado 102 trasplantes, por 64 equipos quirúrgicos, en 24 países, los que habían sido seguidos de fracaso tras fracaso, por lo que el trasplante de corazón fue abandonado por la gran mayoría de los cirujanos cardiacos, efectuándose en 1971 solo 10 trasplantes ${ }^{3}$.

Entre los que persistieron, destaca el grupo de SHUMWAY, en la Universidad de Stanford, los que silenciosamente fueron consiguiendo un avance sostenido, con fondos del NIH. Los esfuerzos se dirigieron primero al diagnóstico precoz del rechazo agudo, ya que esto era crucial para la sobrevida de los pacientes. Así, se establecieron criterios clínicos, electrocardiográficos y ecocardiográficos de rechazo, los que permitieron un tratamiento oportuno y agresivo de este. Se observó que la incidencia y severidad del rechazo era significativamente mayor en los primeros 2 meses y luego disminuían progresivamente. Sin embargo, luego se observó que un grupo de pacientes hacían un "rechazo agudo tardío", aunque este era menos agresivo que el anterior y podía ser tratado exitosamente solo con prednisona. Distinto resultó ser el "rechazo crónico", el que se manifestaba como una vasculopatía difusa del corazón injertado, siendo la principal causa de muerte en el largo plazo $2,3,18$. En 1973 SHUMWAY introduce la "Biopsia Percutánea Transvenosa Endomiocárdica", con lo que fue posible hacer una correlación definitiva entre los cambios histológicos en el miocardio y los síntomas y signos de rechazo ${ }^{19}$. Para 1974, Stanford ya acumulaba un total de 59 trasplantes cardiacos, con una sobrevida de $43 \%$ al año, $40 \%$ a los 2 años y $26 \%$ a los 3 años. Sin embargo, para que el trasplante cardiaco se convirtiera en un tratamiento efectivamente exitoso era necesario desarrollar un mejor tratamiento inmunosupresor.

La etapa moderna. Esta se inicia con la Cyclosporina A, la que fue paulatinamente introducida, primero in vitro, luego en animales y por último en humanos. Esta es un metabolito fúngico aislado de muestras de tierra nórdicas. BOREL comunicó en 1976 por primera vez 
los efectos inmunosupresores de la Cyclosporina A, la que actúa selectivamente sobre los linfocitos ${ }^{20}$. En 1978, en The Lancert, se comunicaron 2 trabajos experimentales en animales, uno de los cuales era en corazón de cerdo, demostrándose no solo su efectividad inmunosupresora, sino que además, su baja toxicidad ${ }^{21}$. SHUMWAY rápidamente comenzó a experimentar con Cyclosporina A, para incorporarla a la práctica clínica en 1980 , definiendo protocolos para su uso ${ }^{22}$. Con esto, en 5 años la sobrevida mejoró a $83 \%, 75 \%$ y 70\%, a 1 , 2 y 3 años, respectivamente, lo que originó un creciente y exponencial interés nuevamente en el trasplante de corazón, en todo el mundo, incluido Chile. Así, en 1987 se reintroduce en nuestro país el trasplante cardiaco en el Hospital Clínico de la Universidad Católica, el que se desarrolla muy paulatinamente, con menos de un trasplante por año en promedio, hasta 1998, año en el que se efectúan 6 trasplantes cardiacos y al año siguiente se efectúan $10^{23}$. Este revivir del trasplante cardiaco se extiende a todo el país, efectuándose ese año 1999 un total de 22 trasplantes en Chile, con lo que el trasplante cardiaco deja de ser un procedimiento excepcional para el tratamiento de la insuficiencia cardiaca terminal en nuestro país.

La muerte cerebral. Christiaan Barnard no solo llevo a cabo el primer trasplante de corazón humano, sino que también fue el primer cirujano en utilizar el corazón de una víctima de un accidente en "muerte cerebral", con lo que cambió el concepto de muerte para siempre. Hasta ese momento, la muerte de un ser humano consistía en la pérdida irreversible de las funciones del corazón y los pulmones. Al cumplirse 50 años de este primer trasplante de corazón, si bien el concepto de muerte cerebral es ampliamente aceptado, muchas de las controversias a las que este ha dado origen aún persisten. Para gran parte del público lego, e incluso para algunos profesionales de la salud, un paciente en muerte cerebral "esta para todos los propósitos muerto, pero no realmente muerto" 24 .

La transición desde muerte cardiaca a muerte cerebral, comenzó, se podría decir, como señala De Georgia ${ }^{24}$, en 1947, cuándo CLAUDE BECK, en Cleveland, efectuó la primera desfibrilación exitosa en un corazón huma- no: sorpresivamente, la muerte se hizo "reversible" 25 . Tres años después, en 1950, BOWER y BENNETT 26 desarrollan la ventilación mecánica por presión positiva y en 1955 se fabrica en forma industrial el primer ventilador mecánico, el Bird Mark 7, dando origen a serios y nuevos problemas diagnósticos, pronósticos y éticos en los pacientes comatosos por lesiones cerebrales: "La pregunta es, ¿está el paciente vivo o muerto?”. En 1957 el Papa Pío XII sentencia que los médicos no están obligados a llevar a cabo tratamientos "extraordinarios" en casos que se consideren "desesperanzados" medicamente y, finalmente, en 1965, la American Medical Association formula las guías para el término de la vida 24 . En paralelo con esta transición de la muerte desde el corazón al cerebro, comienzan los trasplantes de órganos, como más arriba se relata, desde el primer trasplante de riñón en 1954 al primer trasplante de corazón en 1967. Si bien lo habitual inicialmente era usar órganos de cadáveres propiamente tal, los resultados no eran buenos y rápidamente fue madurando la idea de que el uso de "donantes vivos" mejoraría los resultados. En 1966 GUY ALEXANDRE, cirujano belga, define 5 criterios que permitirían declarar la muerte de un individuo y con esto extraer sus órganos para trasplantarlos: 1) midriasis bilateral; 2) ausencia de reflejos; 3) apnea sostenida; 4) hipotensión progresiva con requerimiento de drogas vasoactivas; 5) EEG plano, lo qué inmediatamente genero una gran controversia ${ }^{24}$. En enero de 1968 se formó el Ad Hoc Committee de la Universidad de Harvard para formular una nueva definición de la muerte. Luego de mucha discusión, el comité publicó el 5 de agosto de ese año, en JAMA, una definición del "Coma Irreversible" y de la "Muerte Cerebral" 27 . La preocupación principal del comité fue crear un mecanismo que permitiera la suspensión de las medidas de soporte artificial de la vida en pacientes en coma irreversible o en muerte cerebral. El que con esto fuera posible extraer el corazón de una persona en estas condiciones para trasplantarlo en otra, fue un efecto secundario, pero de enorme importancia, para el desarrollo de los trasplantes en general y del trasplante de corazón en particular, si bien la discusión respecto a la muerte cerebral continuó por muchos años más, y fue seguida por numerosos otros comités y declaraciones 24 . 


\section{Referencias}

1- BARNARD CN. A human cardiac transplant. An interim report of a successful operation performed at Groote Schuur Hospital, Cape Town. S Afr Med J 1967;41:1271-4.

2- DiBARDINO DJ. The history and development of cardiac transplantation. Tex Heart Inst J 1999;26:198-205.

3- PATTERSON C, PATTERSON KB. The history of heart transplantation. Am J Med Sci 1997;314:190-7.

4- CARREL A, GUTHRIE CC. The transplantation of veins and organs. Am Med 1905;10:1101-2.

5- MANN FC, PRIESTLEY JT, MARKOWITZ J, YATER WM. Transplantation of the intact mammalian heart. Arch Surg $1933 ; 26: 219-24$.

6- MARCUS E, WONG SN, LUISADA AA. Homologous heart grafts: transplantation of the heart in dogs. Surg Forum 1951;2:212-7.

7- MURRAY JE, MERRILL JP, HARRISON JH. Renal homotransplantations in identical twins. Surg Forum 1955;6:432-6.

8- ZALAQUETT R. Cincuentenario de la máquina corazón-pulmón. Rev Méd Chile 2003;131:1337-44.

9- WEBB WR, HOWARD HS. Cardio-pulmonary transplantation. Surg Forum 1957;8:313-7.

10- HARDY JD, CHAVEZ CM, KURRUS FD, NEELY WA, ERASLAN S, TURNER MD, et al. Heart transplantation in man. Developmental studies and report of a case. JAMA 1964;188:1132-40.

11- LOWER RR, STOFER RC, SHUMWAY NE. Homovital transplantation of the heart. J Thorac Cardiovasc Surg 1961;41:196-204.

12- RIBATTI D. Peter Brian Medawar and the discovery of acquired immunological tolerance. Immunology Letters 2015;167:63-66.

13- MEDAWAR PB. The behavior and fate of skin autografts and skin homografts in rabbits: a report to the War Wounds Committee of the Medical Research Council J Anat 1944;78:176-99.

14- MURRAY JE, MERRILL JP, DAMMING GJ, DEALY JB, ALEXANDRE GW, HARRISON JH. Kidney transplantation in modified recipients. Ann Surg 1962;156:337-355.
15- KANTROWITZ A, HALLER JD, JOOS H, CERRUTI MM, CARTENSEN HE. Transplantation of the heart in an infant and an adult. Am J Cardiol 1968;22:782-90.

16- STINSON EB, DONG E, SCHROEDER JS, HARRISON DC, SHUMWAY NE. initial experience with heart transplantation. Am J Cardiol 1968;22:791-803.

17- COOLEY DA, HALLMAN GL, BLOODWELL RD, NORA JJ, LEACHMAN RD. Human heart transplantation. Experience with twelve cases. Am J Cardiol 1968;22:804-10.

18- CLARK DA, SCHROEDER JS, GRIEPP RB, STINSON EB, DONG E, SHUMWAY NE. Cardiac transplantation in man. Review of first three years' experience. Am J Med 1973;54:563-76.

19- CAVES PK, STINSON EB, GRAHAM AF, BILLINGHAM ME, GREHL TM, SHUMWAY NE. Percutaneous transvenous endomyocardial biopsy. JAMA 1973;225:288-91.

20- BOREL JF. Comparative study of in vitro and in vivo drug effects on cell-mediated cytotoxicity. Immunology 1976;31:631-41.

21- GREEN CJ, ALLISON AC. Extensive prolongation of rabbit kidney allograft survival after short-term cyclosporine-A treatment. Lancet 1978;1:1182-3.

22- McGREGOR CG, OYER PE, SHUMWAY NE. Heart and heart-lung transplantation. Prog Allergy 1986;38:346-65.

23- MORAN S, CASTRO P, ZALAQUETT R, BECKER P, GARAYAR B, IRARRÁZAVAL MJ et al. Tratamiento de la insuficiencia cardiaca avanzada mediante trasplante de corazón. Rev Méd Chile 2001;129:9-17.

24- DE GIORGIA MA. History of brain death as death: 1968 to the present. J Crit Care 2014;29:673-8.

25- BECK CS, PRITCHARD WH, FEIL HS. Ventricular fibrillation of long duration abolished by electrical shock. J Am Med Assoc 1947;135:985.

26- BOWER AG, BENNETT VR, DILLON JB, AXELROD B. Investigation on the care and treatment of poliomyelitis patients. Ann West Med Surg 1950;4:561-82.

27- A definition of irreversible coma. Report of the Ad Hoc Committee of the Harvard Medical School to Examine the Definition of Brain Death. JAMA 1968;205:337-40. 